\title{
Diagnostic and Prognostic Validity of Serum Golgi Protein 73 in Egyptian Patients with Hepatocelluar Carcinoma
}

\author{
Mohamed N. El Khashab ${ }^{1}$, Soha E. Khorshed ${ }^{1}$, Mostafa M. Toam ${ }^{2}$, \\ Hanaa Abdelmoety ${ }^{3}$, Shereen M. Awad ${ }^{4}$ \\ ${ }^{I}$ Tropical Medicine Department, Faculty of Medicine, Zagazig University, Egypt \\ ${ }^{2}$ Radiotherapy Department, Faculty of Medicine, Zagazig University, Egypt, \\ ${ }^{3}$ Clinical Pathology Department, Faculty of Medicine, Zagazig University, Egypt, \\ ${ }^{4}$ Family Medicine Department, Faculty of Medicine, Zagazig University, Egypt
}

Corresponding Author: Soha E Khorshed

Mobile: +20122457835 8

\section{E mail:} sohaesmat@hotmail.c om

Key words: HCC, GP73, AFP
Background and study aim : Hepatocellular carcinoma (HCC) is common all over the world. Most HCC are diagnosed at an advanced stage. We aimed to detect the serum Golgi protein (GP 73) in patients with cirrhosis and $\mathrm{HCC}$ as non-invasive marker for diagnosis and prognosis of HCC. Patients and Methods: This study was conducted on 81 subjects: They were divided into 3 groups : 27 patients with HCC, 27 patients with liver cirrhosis and 27 healthy control subjects. Serum alphaphetoprotein (AFP) and GP 73 were estimated by ELISA. In addition, GP 73 was remasured after therapy in patients with HCC who were treated by percutaneous ethanol injection. Results: GP 73 was elevated in patients with HCC and liver cirrhosis ; serum level was high in HCC patients $(\mathrm{p}<0.01)$ when compared with the other studied groups.
GP 73 had sensitivity of $81.4 \%$ and specificity of $100 \%$ at a cut-off value $4.12 \mathrm{ng} / \mathrm{ml}$ with area under the receiver operator characteristics (AUC) of 0.964 when compared with AFP that showed a sensitivity $77.7 \%$, specificity $85.1 \%$ at a cut-off value $>200$ and (AUC) 0.774 . when AFP was combined with GP73 for the diagnosis of HCC, sensitivity and specificity were increased to $87.6 \%$ and $100 \%$ respectively. At six week after ethanol injection, a significant decrease in GP73 occurred.

Conclusion: Serum GP 73 can be used as a useful biomarker to confirm the diagnosis of HCC especially if combined with AFP and GP73 had promising prognostic value as it decreased after the treatment of HCC and is correlated to tumor size

\section{INTRODUCTION}

Hepatocellular carcinoma (HCC) is the fifth most common cancer type, and the third leading cause of cancer mortality worldwide [1],[2]. Reports show that HCC is becoming more wide-spread and has dramatically increased in North America, Western Europe and Japan $[\mathbf{3 , 4}]$. Additionally there is an increasing incidence of the disease among younger age groups that warrants further investigations [1].

Egypt has the rising rates of hepatocellular carcinoma (HCC). Egypt's unique nature of liver disease presents questions regarding the etiology of HCC. The currently increasing incidence of HCC in Egyptians may be due to shift of the relative importance of $\mathrm{HCV}$ as primary risk factors [5]. HCC is the second most frequent cause of cancer incidence and mortality among men at Egypt [6].

Many observational studies have reported that HCC is diagnosed at an earlier stage in patients who received surveillance [7]. Although HCC surveillance programs are controversial, most international societies - the European Association for the Study of the Liver and the American Association for the Study of Liver Diseases recommend the use of ultrasound and alphafetoprotein (AFP) in patients with a high risk of developing the condition, at 6-12 months frequency [8]. The use of AFP alone is strongly discouraged, and its use, in addition to ultrasound is controversial. Patients with abnormal screening tests require additional investigations. 
Therefore, there is a strong demand by clinicians for new HCC specific biomarkers. Golgi protein (GP73) is a resident type transmembrane protein expressed primarily in human epithelial cells [9]. In the normal human liver, GP73 is expressed in biliary epithelial cells, but detection is negligible in hepatocytes. However, upregulated expression of GP73 has been identified in hepatic cells in liver disease [10]. Previous studies have also shown increased serum GP73 levels in patients with chronic liver disease and, in particular, in HCC patients. This phenomenon may be due to migration of the GP73 protein to the plasma membrane and diffusion into the circulation $[11,12]$. Thus, the aim of this study is to assess the value of Golgi Protein 73 (GP73) as a noninvasive marker for diagnosis and prognosis of HCC.

\section{PATIENTS AND METHODS}

This study was carried out in Tropical Medical, Radiotherapy and Clinical Pathology Departments, Zagazig University Hospital. This study was conducted on eighty one subjects. The subjects were classified to three groups :

Group I: 27 patients with HCC.

Group II: 27 patients with liver cirrhosis without HCC.

Group III: 27 normal individuals as a control group.

\section{Inclusion criteria:}

1. Patients with HCC (diagnosed by ultrasound and triphasic computed tomography (CT) criteria)

2. Cirrhotic patients with no evidence of hepatic focal masses in ultrasound evaluation, included in group B.

3. Diagnosis of cirrhosis was based on clinical, laboratory, and imaging. Patients with cirrhosis and elevated AFP, but no evident focal hepatic lesion on ultrasound, were subjected to triphasic CT performed within 3 months before and 6 months after the enrollment in the study.

\section{Exclusion criteria :}

All patients who had a prior locoregional therapy, systemic therapy and/or any surgical intervention (liver resection or transplantation) were excluded from the analysis. Also Patients with any other hepatic or non hepatic malignancy.

\section{All patients were subjected to:}

1. Full history taking:

2. Complete general examination.

3. Local examination.
4. Investigations including:

a) Laboratory investigations:

- Complete blood picture (CBC).

- Liver profile: S. bilirubin, SGOT, SGPT, ALP, total protein and S.albumin.

- Kidney profile: S. creatinine, Bl. Urea, and uric acid.

-Coagulation profile: PT, PTT and INR.

- Viral markers:

a- Hepatitis B surface antigen (HBsAg).

b- Hepatitis C immunoglobulin G (HCV $\mathrm{IgG})$.

- Alpha-feto protein ( $\alpha$-FP): It was determined by ELISA Kit For Alphafeto protein $(\alpha-\mathrm{FP})$ provided by Ray Biotech, Inc., the catalogue no ELHAFP. The RayBio® Human AFP (Alpha Fetoprotein) ELISA kit is an in vitro enzyme linked immunosorbent assay for the quantitative measurement of human AFP in serum, plasma, and cell culture supernatants.

- Golgi Protein 73 (GP 73): It was determined by ELISA Kit For Golgi Protein 73 (GP73) provided by Uscn, Life Science (Inc-USA), the catalogue no E91668Hu. The kit is a sandwich enzyme immunoassay for the in vitro quantitative measurement of GP73 in human serum, plasma and other biological fluids.

b) Imaging studies:

- Abdominal ultra-Sonography (U/S) : It was done for examination of the liver for criteria of cirrhosis, presence of focal lesions and measurement of their bipendicular dimensions, patency of portal vein, presence of splenomegaly and ascites.

- Tri-phasic CT

Follow up: GP73 was repeated after the end of percutaneous ethanol injection (PEI) by one and half month. The number of PEI sessions depended on the size of each focal lesion according to the equation: $4 / 3 * 22 / 7 *(1 / 2 \mathrm{r}+1 / 2) 3$. Tri-phasic CT was repeated 6 months after therapy.

\section{Statistical analysis :}

All data were analyzed using SPSS 15.0 for windows (SPSS Inc., Chicago, IL, USA) \& Med Calc 13 for windows (MedCalc Software bvba). 
Continuous variables were expressed as the mean $\pm \mathrm{SD}$ and median (range), and the categorical variables were expressed as a number (percentage). Continuous variables were checked for normality by using Kolmogorov-Smirnov test. Independent Student t-test was used to compare normally distributed variables between two groups. Mann Whitney U (MW) test was used to compare non-normally distributed variables between two groups. GP73 pre-treatment and posttreatment were compared using Wilcoxon signed ranks test. Percent of categorical variables were compared using the Chi-square $\left(\chi^{2}\right)$ test.

Spearman's rank correlation analysis was done between GP73 levels and all study parameters. Receiver operating characteristic (ROC) curve analysis was used to identify optimal cut-off values of GP73 with maximum sensitivity and specificity for differentiation of patients with HCC from those without HCC.

$\mathrm{P}<0.05$ was considered statistically significant (S), $\mathrm{p}<0.005$ was considered highly statistically significant (HS), and $\mathrm{p} \geq 0.05$ was considered non statistically significant (NS). p1 denote $\mathrm{p}$ value of test of significance between group I \& group II, p2 denote $\mathrm{p}$ value of test of significance between group I \& group III \& p3 denote p value of test of significance between group II and group III.

\section{RESULTS}

This study was conducted on 81 subjects, divided into 3 groups 27 subjects in each group, group I (HCC patients), group II (liver cirrhosis) and group III (Healthy control group).

As regard the demographic data, there was a highly significant difference between the three studied groups according to the age with mean age 58.44 years in group I, 53.96 years in group II and 50.48 in group III (p1<0.002, p2<0.001 and $\mathrm{p} 3<0.003)$. Meanwhile, according to sex, there was no significant difference between the three groups. There were 23 males $(85.2 \%)$ and 4 females $(14.8 \%)$ in group I, 22 males $(81.5 \%)$ and 4 females $(18.5 \%)$ in group II and 22 males $(81.5 \%)$ and 5 females $(18.5 \%)$ in group III. In addition to, the laboratory data, there was a highly significant difference between the three studied groups in the level of total bilirubin, serum albumin, ALT, AST, hemoglobin, platelet count and prothrombin concentration when HCC and liver cirrhosis group compared to the control group (p2<0.001 and p3<0.001) (Table 1).

As regard to the clinical data, there was no significant difference between the HCC group and liver cirrhosis group according to jaundice, hepatomegaly, splenomegaly, lower limb edema and ascites ( $p>0.05)$.

Comparison between group I and group II as regard Child-Pugh classification, ascites, encephalopathy, viral etiology revealed no significant difference ( $>0.05)$. In group I there were 5 patients with Child A (18.5\%) and 22 patients with Child B (81.5\%), in group II, there were 6 patients with Child A (22.2\%) and 21 patients with Child B (77.8\%). In group I, there were $19 \mathrm{HCV}$ positive patients (70.4\%), $5 \mathrm{HBV}$ positive patients (18.5\%) and 3patinets with positive $\mathrm{HBV} \& \mathrm{HCV}$ (11.1\%). In group II, there were $18 \mathrm{HCV}$ positive patients $(66.7 \%), 7 \mathrm{HBV}$ positive patients $(25.9 \%)$ and 2 patients with positive HBV \& HCV (7.4\%) (Table 2).

All the HCC patients included in this study were with single focal lesion (100\%); with mean dimensions $2.67 \mathrm{~cm} \times 2.67 \mathrm{~cm} \pm 0.52$ and mean biperndicular diameter $7.39 \mathrm{~cm}^{2} \pm 2.77$ and all patients show no PVT.

Comparison between the three studied groups as regard AFP and GP73 shows high significance with mean level of AFP $552.35 \mathrm{ng} / \mathrm{ml}$ in group I, $16.43 \mathrm{ng} / \mathrm{ml}$ in group II and $1.98 \mathrm{ng} / \mathrm{ml}$ in group III (p1, p2 and p3 <0.001). Meanwhile, GP73 showed mean level of $8.86 \mathrm{ng} / \mathrm{ml}$ in group I, 4.53 $\mathrm{ng} / \mathrm{ml}$ in group II and $2.19 \mathrm{~g} / \mathrm{ml}$ in group III (p1,p2 and p3 <0.001) (Table 3).

Correlation between tumor markers and all study parameters in the HCC group showed high significance correlation between GP73 and AFP and vice versa and between size of tumor with both AFP and GP73 ( $<<0.001)$. The size of HCC foci ranged from 1.7 to $3.7 \mathrm{~cm}$ with a mean diameter of $2.7 \pm 1.0 \mathrm{~cm}$ (Figure 2,3)

At a cut-off value $4.12 \mathrm{ng} / \mathrm{ml}, \mathrm{GP} 73$ showed a sensitivity of $81.4 \%, 100 \%$ specificity and AUC of 0.964 with accuracy of $90.7 \%$ when compared to the control group. And at a cut-off value of 6.7 $\mathrm{ng} / \mathrm{ml}$, GP73 showed a sensitivity of $81.4 \%$ and 92.5\% specificity and AUC of 0.812 with accuracy of $87 \%$ versus cirrhotic control (Table 4). The sensitivity and specificity of AFP at a cut-off value $200 \mathrm{ng} / \mathrm{ml}$ was $77.7 \%$ and $85.1 \%$ respectively with AUC of 0.774 versus healthy 
control (accuracy 81.4\%). Meanwhile, versus cirrhotic patient, AFP showed sensitivity and specificity of $74.1 \%$ and $66.7 \%$ respectively with AUC 0.698 (accuracy 70.4\%) (Table 5).

However, when GP73 used in combination with AFP in early diagnosis of HCC, they increased the sensitivity to $87.6 \%$ and the specificity to $100 \%$ with increasing of AUC to .977 versus the control group and $88.9 \%$ and $95.7 \%$ for the sensitivity and the specificity versus cirrhotic group respectively with increasing AUC, also to 0.905 (Table 6).

All the chosen HCC patients were treated with percutaneous ethanol injection. The mean level of GP73 before and after treatment showed decrease with mean level $8.86 \mathrm{ng} / \mathrm{ml}$ and 5.8 $\mathrm{ng} / \mathrm{ml}$ pre-treatment and post-treatment respectively $(\mathrm{WSR}=-3.436, \mathrm{p}<0.001)($ Table 7$)$.

Table (1) : Comparison between the studied groups as regard the demographic and laboratory data

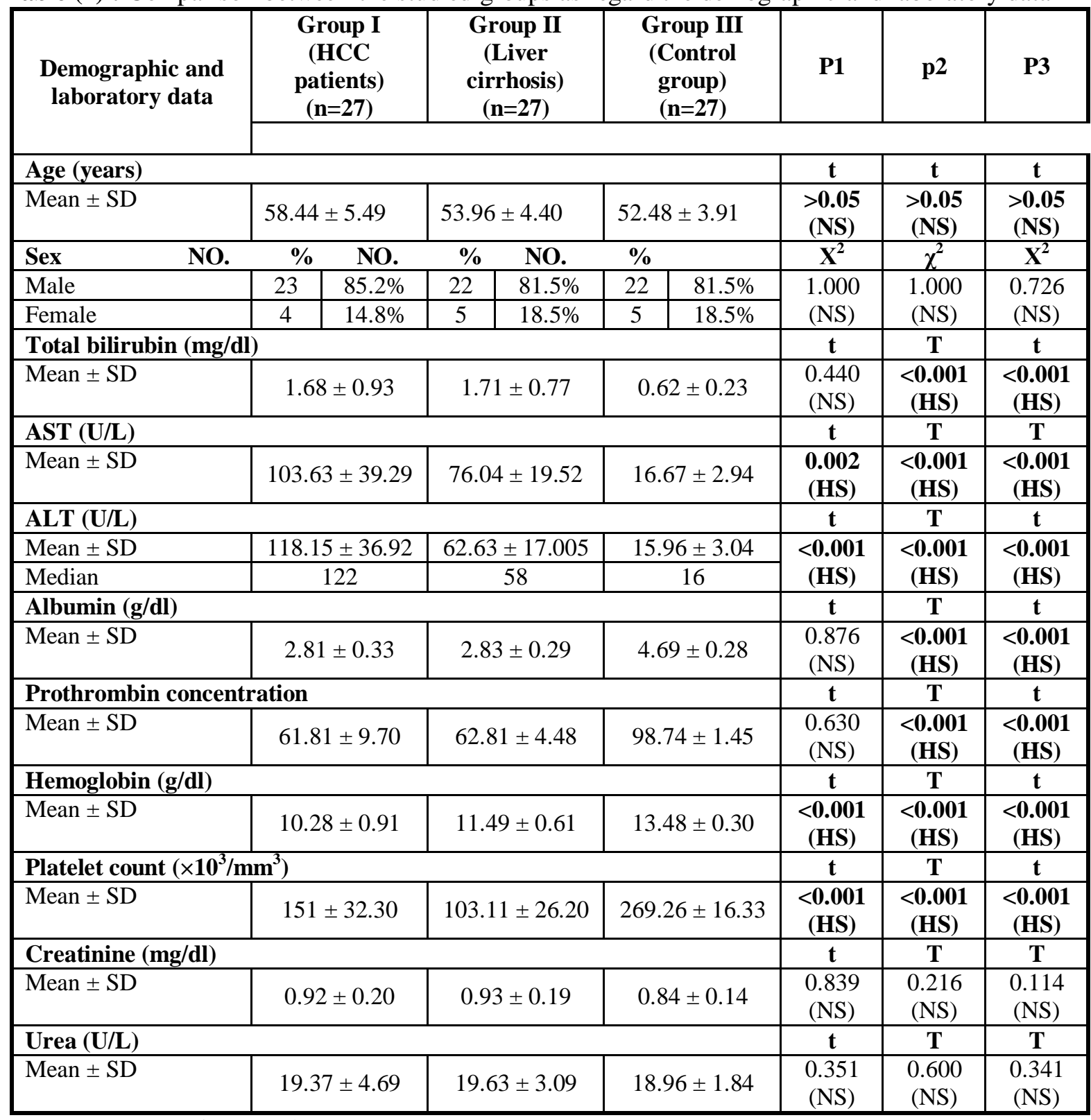

$P$ value by man-whitney test)
$\chi^{2}$ : Chi-square test
t: independent Student t-test
$\mathrm{p}<0.05$ is significant

p1 denote p value of test of significance between group I \& group II

p2 denote $p$ value of test of significance between group I \& group III

p3 denote $p$ value of test of significance between group II \& group III 
Table (2) : Comparison between group I and group II as regard Child-Pugh classification and viral etiololgy

\begin{tabular}{|c|c|c|c|}
\hline & $\begin{array}{c}\text { Group I } \\
\text { HCC } \\
(\mathbf{n}=27) \\
\end{array}$ & $\begin{array}{c}\text { Group II } \\
\text { Cirrhosis } \\
(\mathbf{n}=27)\end{array}$ & $\mathbf{P}$ \\
\hline \multicolumn{4}{|c|}{ Child-pugh class. } \\
\hline $\mathrm{A}$ & $5(18.5 \%)$ & $6(22.2 \%)$ & $\mathrm{NS}$ \\
\hline B & $22(81.5 \%)$ & $21(77.8 \%)$ & $\mathrm{NS}$ \\
\hline $\mathrm{C}$ & 0 & 0 & $\mathrm{NS}$ \\
\hline \multicolumn{4}{|l|}{ Viral infection } \\
\hline $\mathrm{HBV}$ & $5(18.5 \%)$ & $7(25.9 \%)$ & $\mathrm{NS}$ \\
\hline $\mathrm{HCV}$ & $19(70.4 \%)$ & $18(66.7 \%)$ & $\mathrm{NS}$ \\
\hline $\mathrm{HBV} \& \mathrm{HCV}$ & $3(11.1 \%)$ & $2(7.4 \%)$ & NS \\
\hline
\end{tabular}

Table (3) : Comparison between the studied groups as regard AFP and GP73

\begin{tabular}{|c|c|c|c|c|c|c|}
\hline Tumor markers & $\begin{array}{c}\text { Group I } \\
\text { (HCC patients) } \\
(\mathbf{n = 2 7})\end{array}$ & $\begin{array}{c}\text { Group II } \\
\text { (Liver } \\
\text { cirrhosis) } \\
(\mathbf{n}=\mathbf{2 7}) \\
\end{array}$ & $\begin{array}{c}\text { Group III } \\
\text { (Control } \\
\text { group) } \\
(\mathbf{n}=27) \\
\end{array}$ & p1 & p2 & p3 \\
\hline \multicolumn{4}{|l|}{$\mathrm{AFP}(\mathrm{ng} / \mathrm{ml})$} & $\mathbf{t}$ & $\mathbf{T}$ & $\mathbf{T}$ \\
\hline Mean \pm SD & $552.35 \pm 169.05$ & $16.43 \pm 3.49$ & $1.95 \pm 0.11$ & \multirow{2}{*}{$\begin{array}{c}<0.001 \\
(\mathrm{HS})\end{array}$} & \multirow{2}{*}{$\begin{array}{c}<0.001 \\
\text { (HS) }\end{array}$} & \multirow{2}{*}{$\begin{array}{c}<0.001 \\
\text { (HS) }\end{array}$} \\
\hline Range & $208-865$ & $9.45-23$ & $1.72-2.13$ & & & \\
\hline \multicolumn{4}{|l|}{ GP73 (ng/ml) } & MW & MW & MW \\
\hline Mean \pm SD & $8.86 \pm 3.24$ & $4.53 \pm 1.86$ & $2.19 \pm 0.74$ & \multirow{2}{*}{$\begin{array}{c}<0.001 \\
(\mathrm{HS})\end{array}$} & \multirow{2}{*}{$\begin{array}{c}<0.001 \\
(\mathrm{HS})\end{array}$} & \multirow{2}{*}{$\begin{array}{c}<0.001 \\
(\mathrm{HS})\end{array}$} \\
\hline Range & $2.2-12.5$ & $1.99-11$ & $1.0-4.12$ & & & \\
\hline
\end{tabular}

$\mathrm{t}$ : independent Student t-test

MW: Mann Whitney U test

$\mathrm{p}<0.05$ is significant

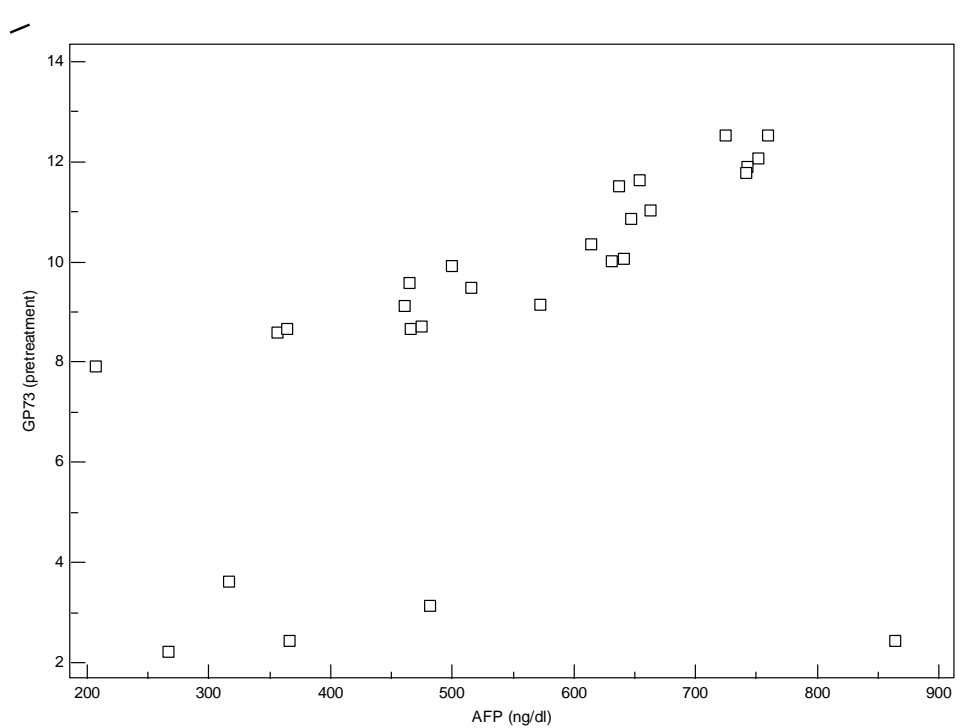

Figure (1): Scatter plot with regression line shows correlation between AFP (ng/ml) \& pretreatment GP73 $(\mathrm{r}=+0.968, \mathrm{p}<0.001)$. 


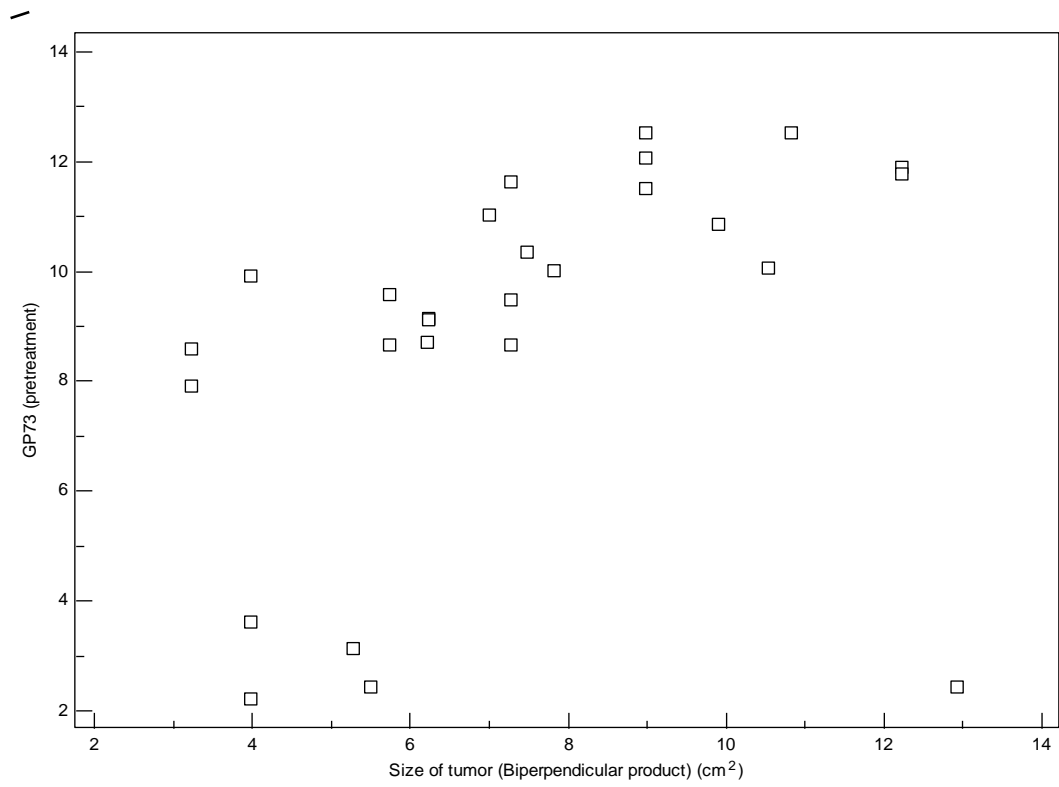

Figure (2): Scatter plot with regression line shows correlation between size of tumor (Biperpendicular product) \& pretreatment GP73 $(\mathrm{r}=+0.861, \mathrm{p}<0.001)$.

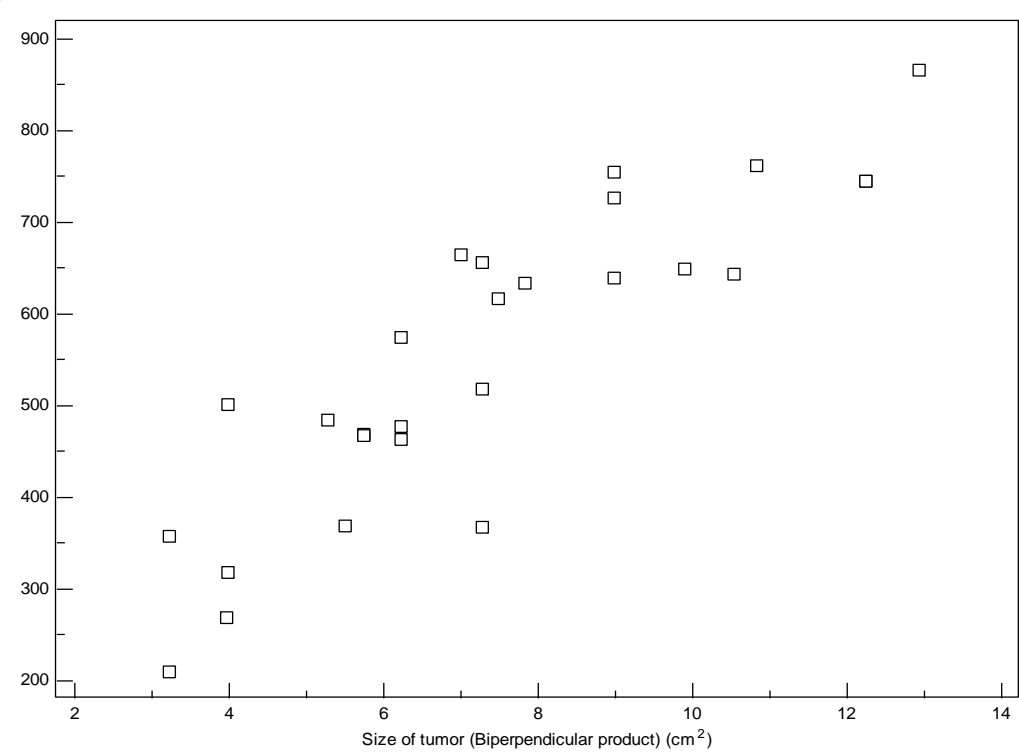

Figure (3): Scatter plot with regression line shows correlation between Size of tumor (Biperpendicular product) $\&$ AFP $(r=+0.876, \mathrm{p}<0.001)$. 
Table (4) : GP73 as a diagnostic marker for HCC (versus cirrhosis)

\begin{tabular}{|c|c|c|c|c|c|}
\hline Cut-off value & $\begin{array}{c}\text { Sens. \% } \\
(95 \% \text { CI })\end{array}$ & $\begin{array}{c}\text { Spec. \% } \\
(95 \% \text { CI })\end{array}$ & $\begin{array}{c}\text { PPV \% } \\
(95 \% \text { CI })\end{array}$ & $\begin{array}{c}\text { NPV \% } \\
(95 \% \text { CI })\end{array}$ & $\begin{array}{c}\text { AUC* } \\
(95 \% \text { CI })\end{array}$ \\
\hline$>\mathbf{6 . 7}$ & $\begin{array}{c}81.4 \% \\
(61.9-93.7)\end{array}$ & $\begin{array}{c}92.5 \% \\
(75.7-99.1)\end{array}$ & $\begin{array}{c}91.7 \% \\
(73-99)\end{array}$ & $\begin{array}{c}83.3 \% \\
(65.3-94.4)\end{array}$ & $\begin{array}{c}0.812 \ddagger \\
(0.683-0.905)\end{array}$ \\
\hline
\end{tabular}

* Accuracy of GP73 as a diagnostic marker for HCC (versus cirrhosis) = 87\% (68.8 - 96.4) (Excellent). $+\mathbf{p}<0.0001($ HS)

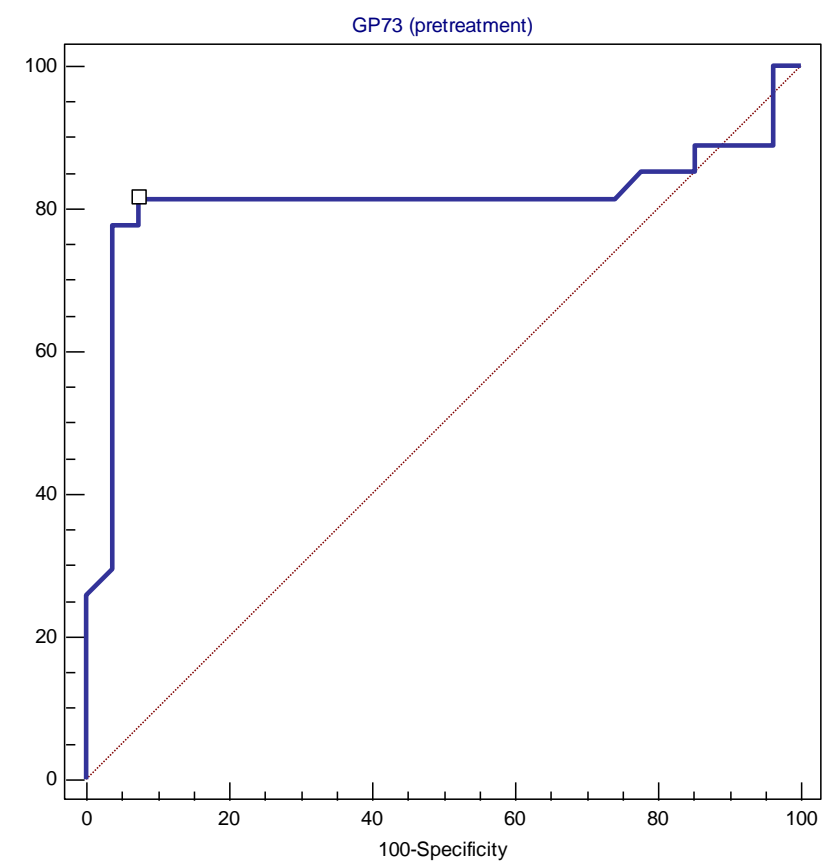

Figure (4): Receiver operating characteristic (ROC) curve of GP73 as a diagnostic marker for HCC (versus cirrhosis).

Table (5) : Validity of GP73 versus AFP in prediction of HCC among HCC (versus healthy)

\begin{tabular}{|c|c|c|c|c|c|}
\hline Cut-off values & $\begin{array}{c}\text { Sens. \% } \\
(95 \% \text { CI })\end{array}$ & $\begin{array}{c}\text { Spec. \% } \\
(95 \% \text { CI })\end{array}$ & $\begin{array}{c}\text { PPV \% } \\
(95 \% \text { CI })\end{array}$ & $\begin{array}{c}\text { NPV \% } \\
(95 \% \text { CI })\end{array}$ & $\begin{array}{c}\text { AUC* } \\
(95 \% \text { CI })\end{array}$ \\
\hline GP73 > 4.12 & $81.4 \%$ & $100 \%$ & $100 \%$ & $84.4 \%$ & $0.964 \ddagger$ \\
& $(61.9-93.7)$ & $(87.2-100)$ & $(84.6-100)$ & $(67.2-94.7)$ & $(0.875-0.996)$ \\
\hline AFP > 200 & $77.7 \%$ & $85.1 \%$ & $84 \%$ & $79.3 \%$ & $0.774 \S$ \\
& $(57.7-91.4)$ & $(66.3-95.8)$ & $(63.9-95.5)$ & $(60.3-92)$ & $(0.640-0.877)$ \\
\hline Both & $87.6 \%$ & $100 \%$ & $100 \%$ & $90.1 \%$ & 0.977 \\
\hline
\end{tabular}

* Accuracy of GP73 as a diagnostic marker for HCC (versus healthy control) $=90.7 \%(74.6-96.9)$ (Excellent); Accuracy of AFP as a diagnostic marker for HCC (versus healthy) $=81.4 \%$ (62 - 93.6); Accuracy of both GP73 and AFP 93.4\%

$\ddagger \mathbf{p}<0.001$ (HS)

$\S \mathbf{p}<0.001(\mathbf{H S})$ 
Table (6): Validity of GP73 versus AFP in prediction of HCC among HCC (versus cirrhosis)

\begin{tabular}{|l|c|c|c|c|c|}
\hline Cut-off values & $\begin{array}{c}\text { Sens. \% } \\
(95 \% \text { CI })\end{array}$ & $\begin{array}{c}\text { Spec. \% } \\
(95 \% \text { CI })\end{array}$ & $\begin{array}{c}\text { PPV \% } \\
(95 \% \text { CI })\end{array}$ & $\begin{array}{c}\text { NPV \% } \\
(95 \% \text { CI })\end{array}$ & $\begin{array}{c}\text { AUC* } \\
(95 \% \text { CI })\end{array}$ \\
\hline GP73 > 6.7 & $81.4 \%$ & $92.5 \%$ & $91.7 \%$ & $83.3 \%$ & $0.812 \ddagger$ \\
$(61.9-93.7)$ & $(75.7-99.1)$ & $(73-99)$ & $(65.3-94.4)$ & $(0.683-0.905)$ \\
\hline AFP > 400 & $74.1 \%$ & $66.7 \%$ & $69 \%$ & $72 \%$ & $0.698 \S$ \\
& $(53.7-88.9)$ & $(46-83.5)$ & $(49.2-84.7)$ & $(50.6-87.9)$ & $(0.558-0.816)$ \\
\hline Both & $88.9 \%$ & $95.7 \%$ & $94.3 \%$ & $88.9 \%$ & 0.905 \\
\hline
\end{tabular}

$*$ Accuracy of GP73 as a diagnostic marker for HCC (versus cirrhotic) $=87 \%(68.8-96.4)$ (Excellent). Accuracy of AFP as a diagnostic marker for HCC (versus cirrhotic) $=70.4 \%(49.9-86.2)$.

$\$ \mathrm{p}<0.001$ (HS)

$\S \mathrm{p}<0.001(\mathrm{HS})$

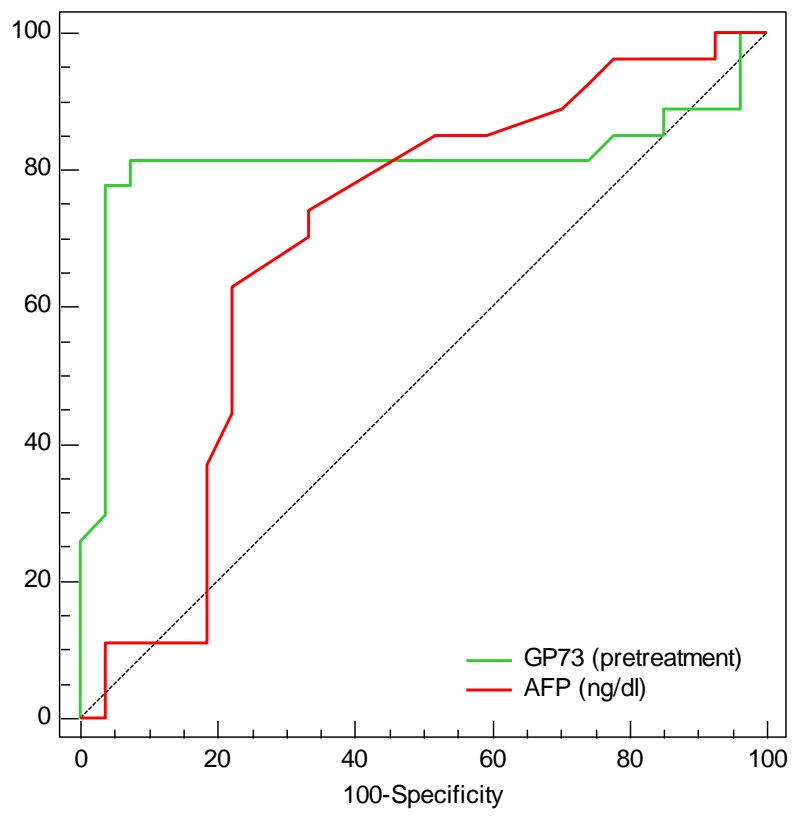

Figure (5): Receiver operating characteristic (ROC) curve of GP73 and AFP as diagnostic markers for HCC (versus cirrhosis).

Table (7): Comparison between GP73 before and after therapy

\begin{tabular}{|l|c|c|c|c|}
\hline & $\begin{array}{c}\text { Pre-treatment GP73 } \\
(\mathbf{n = 2 7})\end{array}$ & $\begin{array}{c}\text { Post-treatment } \\
(\mathbf{n}=\mathbf{2 7})\end{array}$ & WSR & $\mathbf{p}$ \\
\hline Mean \pm SD & $8.86 \pm 3.42$ & $5.80 \pm 2.71$ & \multirow{2}{*}{-3.436} & $\begin{array}{c}<\mathbf{0 . 0 0 1} \\
(\text { HS })\end{array}$ \\
\hline Median (Range) & $9.5(2.2-12.5)$ & $5(1.99-7.5)$ & &
\end{tabular}

WSR: Wilcoxon signed ranks test.

$\mathrm{p}<0.05$ is significant

\section{DISCUSSION}

Hepatocellular carcinoma is usually asymptomatic in early stages and tends to be invasive. Therefore, most patients are presented with an incurable disease at the time of detection which makes its early diagnosis critical for a good prognosis. Surgical resection remains the treatment of choice for these tumors, but unfortunately only $10-20 \%$ of primary HCCs are resectable at time of diagnosis. Continuous researches are ongoing worldwide to find and evaluate an early sensitive and specific marker for HCC [13]. In Egypt, chronic HCV is the main cause of liver cirrhosis and liver cancer, 
which is one of the top five leading causes of death [14].

Serum AFP is the most widely used biomarker for diagnosis of HCC. The normal range for serum AFP levels is $10-20 \mathrm{ng} / \mathrm{ml}$ and a level $>400$ $\mathrm{ng} / \mathrm{ml}$ is usually regarded as of diagnostic value. However, two thirds of HCC patients with the nodule less than $4 \mathrm{~cm}$ have serum AFP levels less than $200 \mathrm{ng} / \mathrm{ml}$ and up to $20 \%$ of $\mathrm{HCC}$ patients do not produce AFP. Therefore, the lack of AFP sensitivity and specificity [15] has elucidated the need for a new tumor marker for differentiating HCC from benign hepatic disorders.

In the present study there was a statistically significant difference between the mean value of GP3 in patients with HCC compared to patients with liver cirrhosis and control with mean values of $8.86 \pm 3.24,4.53 \pm 1.86$ and $2.19 \pm 0.74 \mathrm{ng} / \mathrm{mL}$ respectively with a $p$ value $<0.001$. These findings were in agreement with Riener et al. [16], Gu et al. [17] who demonstrated that elevation of serum levels of GP73 was detected in patients who had developed an HCC on the background of HCV infection in comparison with cirrhotic control. Mao et al. [18] who studied GP73 in viral hepatitis have found that the elevation of serum GP73 is mildest in virus carriers, moderate in patients with cirrhosis and dramatic in patients with HCC. This indicates the performance of GP73 might depend on the etiology of underlying disease. Therefore, serum GP73 can be used to monitor disease progression from HBV infection to cirrhosis to HCC.

These results didn't come in agreement with Ozkan et al. [19] who found that levels of GP73 weren't significantly higher in HCC and cirrhotic patients compared to controls where the median of GP73 was $0.27 \mathrm{ng} / \mathrm{ml}$ in controls, $0.32 \mathrm{ng} / \mathrm{ml}$ in cirrhotic patients and $0.21 \mathrm{ng} / \mathrm{ml}$ in those with HCC with a $\mathrm{p}$ value $>0.05$ which could support the presence of GP73 specific auto antibodies interfering with ELISA analysis.

Regarding the diagnostic value of GP73, the sensitivity and specificity varied with different cut-off points. In our study, GP73 had a sensitivity of $81.4 \%$ and a specificity of $100 \%$ at the optimal cut-off value of $4.12 \mathrm{ng} / \mathrm{ml}$ with AUROC of 0.964 if compared versus healthy control and had a sensitivity of $81.4 \%$ and a specificity of $92.5 \%$ at the optimal cut-off value of $6.7 \mathrm{ng} / \mathrm{ml}$ if compared versus cirrhotic patient with AUC of 0.812 which was similar to the results of Marrero and Lok [20], Gomaa et al.
[21] postulated that, GP73 is up-regulated in HCC and measurement of serum GP73 revealed a sensitivity and specificity of $69 \%$ and $75 \%$ respectively.

In the present study, AFP had a sensitivity of $81.4 \%$ and a specificity of $92.5 \%$ at a cut-off >400. Sarwar et al. [22] found that AFP sensitivity was $42.7 \%$ and its specificity was $100 \%$ at a cut-off value of $>400 \mathrm{ng} / \mathrm{ml}$.

In this study the combination of AFP and GP73 led to enhancing the sensitivity of detection of HCC to $87.6 \%$, the specificity to $100 \%$ and AUROC curve was 0.9777 with an accuracy of 93.4\% which is better than either of them alone. This was in agreement with Wang et al., (2009) [23] and Mao et al. [18].

In our study, the size of focal lesions ranged from $1.8-3.7 \mathrm{~cm}$ as we selected the cases only fit for percutaneous ethanol injection. Daniele et al. [24] said that PEI would be more effective in small focal lesions less than $3 \mathrm{~cm}$.

In our study, there was a decrease in the level of sGP73 after PEI in the HCC group with mean level of $8.86 \mathrm{ng} / \mathrm{ml}$ before PEI and of $5.80 \mathrm{ng} / \mathrm{ml}$ after PEI $(\mathrm{p}<0.001)$ and this was in consistent with Mao et al. [18] who demonstrated that surgical resection of the tumor results in diminished serum GP73 levels and that tumor recurrence correlates with the recurrence of elevated GP73 in the blood. Reappearance of serum GP73 indicates the existence of tumor lesions and thus may serve as an indicator for the recurrence of $\mathrm{HCC}$.

\section{CONCLUSION}

In conclusion, in combination, measurement of both GP73 and AFP has the promise to further improve the detection of HCC. GP73 has a promising prognostic value as it decreased after the treatment of HCC and is correlated to tumor size.

\section{Acknowledgements :}

The authors would like to express their sincere grantitude to the patients and staff if the Tropical Medicine Department, and to the laboratory technecians, for their great endeavor.

\section{Funding:None}

Ethical Approval: This study was approved by the ethical committee of Faculty of Medicine, Zagazig University and all patients provided 
written informed consent before participation in any protocol specific procedure.

Conflicts of interest :There are no conflict of interests

\section{REFERENCES}

1. El-Serag HB , Rudolph KL . Hepato-cellular carcinoma: epidemiology and molecular carcinogenesis. 2007;132:2557-2576.

Gastroenterology

2. Altekruse SF, McGlynn KA, Reichman ME . Hepatocellular carcinoma, incidence, mortality, and survival trends in the United States from 1975 to 2005. J Clin Oncol 2009; 27:1485-1491

3. Nguyen MH, Whittemore AS, Tawfeek SA, Ning $\mathrm{J}$, Lam S, Wright TL, et al. Role of ethnicity in risk for hepato-cellular carcinoma in patients with chronic hepatitis C and cirrhosis. Clin Gastroenterol Hepatol 2004; 2:820-824.

4. Farazi PA , DePinho RA . Hepato-cellular carcinoma pathogenesis: from genes to environment. Na Rev Cancer 2006; 6:674-687.

5. El-Zayadi AR, Badran HM, Barakat EM, Attia Mel-D, Shawky S, Mohamed MK, Selim O, Saeid A . Hepatocellular carcinoma in Egypt: a single center study over a decade. World $J$ Gastroenterol 2005; 11:5193-8.

6. Freedman LS, Edwards BK, Ries LAG, et al. Cancer incidence in four member countries (Cyprus, Egypt, Israel, and Jordan) of the Middle East Cancer Consortium (MECC) compared with US SEER. National Cancer Institute, NIH, Bethesda 2006; pp 06-5873.

7. Cabibbo G, Craxi' A . Epidemiology, risk factors and surveillance of hepatocellular carcinoma. Eur Rev Med Pharmacol Sci 2010; 14:352-355.

8. Bruix J , Sherman M . Management of hepatocellular carcinoma. Hepatology 2005; 42:1208-1236

9. Kladney RD, Bulla GA, Guo L, Mason AL, Tollefson AE, Simon DJ,et al. GP73, a novel Golgi localized protein upregulated by viral infection. Gene 2000;249: 5365.

10. Kladney RD, Cui X, Bulla GA, Brunt EM, Fimmel CJ. Expression of GP73, a resident Golgi membrane protein, in viral and nonviral liver disease. Hepatology $2002 ; 35(6): 1431-40$.

11. Block TM, Comunale MA, Lowman M, Steel LF, Romano PR, Fimmel C, et al. Use of targeted glycoproteomics to identify serum glycoproteins that correlate with liver cancer in woodchucks and humans. Proc Natl Acad Sci U S A 2005; 102:779-784.
12. Comunale MA, Mattu TS, Lowman MA, Evans AA, London WT, Semmes OJ, et al: Comparative proteomic analysis of de $\mathrm{N}$ glycosylated serum from hepatitis B carriers reveals polypeptides that correlate with disease status. Proteomics; 4: 826838.

13. Filmus J, Capurro M . Glypican 3 and alphafetoprotein as diagnostic tests for hepato-cellular carcinoma as diagnostic tests. Mol. Diagn 2004, 8: 207.

14. Giannelli $G$, Antonaci $S$. New frontiers in biomarkers for hepatocellular carcinoma. Dig Liver Dis 2006; 38:854-859.

15. Toyoda H, Kumada T, Osaki Y, Oka H, Kudo M. Role of tumor markers in assessment of tumor progression and prediction of outcomes in patients with hepatocellular carcinoma. Hepatol Res 2007; 37 (Suppl 2): S166-S171

16. Riener MO, Stenner F, Liewen H, Soll C, Breitenstein S, Pestalozzi BC et al. Golgi Phosphoprotein 2 (GOLPH2) Expression in Liver Tumors and Its Value as a Serum Marker in Hepatocellular Carcinomas. Hepatology 2009; 49: 1602-1609.

17. Marrero JA, Romano PR, Nikolaeva O, Steel L, Mehta A, Fimmel CJ, et al. GP73, a resident Golgi glycoprotein, is a novel serum marker for hepatocellular carcinoma. J Hepatol 2005; 43:1007-1012

18. Mao Y, Yang H, Xu H, Lu X, Sang X, Du S et al. Golgi protein 73 (GOLPH2) is a valuable serum marker for hepatocellular carcinoma. Gut; 2010. ;59(12):1687-93.

19. Özkan H, Erdal H, TutkakH, Karaeren Z, Yakut M, Yüksel O, Köklü S. et al. Diagnostic and prognostic validity of Golgi protein 73 in hepatocellular carcinoma. Digestion. 2011;83(12):83-8.

20. Marrero JA , Lok AS . Newer markers for hepatocellular carcinoma.Gastroenterology 2004 ; 127(5 Suppl 1):S113-119.

21. Gomaa AI, Khan SA, Leen EL, Waked I, TaylorRobinson SD. Diagnosis of hepatocellular carcinoma. World J Gastroenterol. 2009 ; 15(11):1301-14.

22. Sarwar S., Khan A and Tarique S. Validity of Alpha Fetoprotein for Diagnosis of Hepatocellular Carcinoma in Cirrhosis. Journal of the College of Physicians and Surgeons Pakistan 2014; 24 (1): 18-22.

23. Wang M, Long RE, Comunale MA, Junaidi O, Marrero J, Di Bisceglie AM, et al. Novel Fucosylated Biomarkers for the Early Detection of Hepatocellular Carcinoma. Cancer Epidemiol Biomarkers Prev 2009; 18:1914-1921. 
24. Daniele B, De Sio I, Izzo F, Capuano G, Andreana A, Mazzanti R, Aiello A, Vallone P, et al. Hepatic resection and percutaneous ethanol injection as treatments of small hepato-cellular carcinoma: a Cancer of the Liver Italian Program (CLIP 08) retrospective case-control study .J Clin Gastroenterol.2003 ;36:63-7.
Peer reviewer: Amira Suliman ,Professor of Tropical Medicine and Hepatogastroenterology, Faculty of Medicine, Zagazig University, Egypt.

Editor: Tarik Zaher, Professor of Tropical Medicine and Hepatogastroenterology, Faculty of Medicine, Zagazig University, Egypt 